\title{
Globe
}

Revue internationale d'études québécoises

Frédéric Smith, "La France appelle votre secours ". Québec et la France libre 1940-1945, Montréal, VLB éditeur, 2012

\section{Marc Bergère}

Volume 15, numéro 1-2, 2012

URI : https://id.erudit.org/iderudit/1014642ar

DOI : https://doi.org/10.7202/1014642ar

Aller au sommaire du numéro

Éditeur(s)

Globe, Revue internationale d'études québécoises

ISSN

1481-5869 (imprimé)

1923-8231 (numérique)

Découvrir la revue

Citer ce compte rendu

Bergère, M. (2012). Compte rendu de [Frédéric Smith, «La France appelle votre secours ». Québec et la France libre 1940-1945, Montréal, VLB éditeur, 2012].

Globe, 15(1-2), 349-351. https://doi.org/10.7202/1014642ar d'utilisation que vous pouvez consulter en ligne.

https://apropos.erudit.org/fr/usagers/politique-dutilisation/ 
historiens plus rigoureux resteront sceptiques devant tant d'affirmations gratuites portant sur un Champlain rêvé et héroïque plus grand que nature.

John A. Dickinson

Université de Montréal

\section{Frédéric Smith}

"La France appelle votre secours». Québec et la France libre 1940-1945, Montréal, VLB éditeur, 2012.

Sous un titre tiré pour partie du vibrant appel lancé par le général de Gaulle aux Canadiens français le $1^{\text {er }}$ août 1940, Frédéric Smith nous propose de revisiter la question de l'implantation et de la diffusion de la France libre au Québec.

Pour ce faire, il utilise une bibliographie maîtrisée, mais qui fait l'impasse sur certains travaux universitaires non publiés. On peut penser ici aux mémoires de maîtrise de Stéphane Dionne, de Jenny-Louise Sexton et de Samuel Trudeau, ou aux thèses de doctorat en histoire de Sylvie Guillaume (Bordeaux III, 1975) et d'Olivier Courteaux (Paris IV, 2000). Smith emploie également des sources primaires originales, en particulier les fonds Auguste Viatte ou Marthe Simard. Utilement illustré, l'ensemble de l'ouvrage est agréable à lire, et propose une édition de bonne facture.

Dans la continuité des travaux existants, notamment ceux d'Éric Amyot, l'auteur confirme ce que les historiens martèlent depuis longtemps: le Québec ne fut ni monolithique ni figé dans son attitude face à Vichy et à la France libre, n'en déplaise aux tenants d'une mémoire hémiplégique! Ainsi, il souligne bien les clivages qui divisent la société québécoise, les vecteurs d'opinion (la presse), les élites et l'Église, au sein de laquelle le Cardinal Villeneuve aurait, dès 1941 selon l'auteur, opéré une discrète surveillance, voire une "épuration " des éléments "les plus ardemment vichystes" (p. 107) : une piste qui mériterait assurément d'être creusée. De même, Smith confirme la nécessité de se doter d'une chronologie fine pour aborder une opinion progaulliste ici comme ailleurs (cf. les travaux de Pierre Laborie en France) très évolutive: de la réticence ou de l'indifférence initiale aux premiers infléchissements de 1941, jusqu'au retournement majoritaire de 1943. Plus encore, il montre la somme des difficultés rencontrées et in fine surmontées. 
D’une part, l'auteur ne néglige pas les hésitations (Auguste Viatte lui-même) et les contradictions ( $\mathrm{M}^{\mathrm{gr}} \mathrm{Roy}$ ) des uns ou des autres. Mieux, il souligne l'ambivalence fréquente des options individuelles ou collectives. Sur ce plan, les attitudes face au général Giraud comme troisième homme sont riches d'enseignements dans la dynamique des analyses d'Éric Amyot. Sous cet angle, le cas d'Antoine de Saint-Exupéry abordé par l'auteur (p. 131-134) est judicieux. Mais, au-delà de son voyage du printemps 1942 et de l'anecdote sur la source d'inspiration réelle du Petit Prince, il semble que l'on aurait pu davantage, et mieux, souligner les ambiguïtés de la position de SaintExupéry à l'égard des deux France, à travers les réactions canadiennes (en particulier des partisans de la France libre ?) à sa fameuse et assez curieuse «lettre ouverte à tous les Français » du 29 novembre 1942, où il plaidait de manière sibylline et un peu à contretemps pour une réconciliation nationale. Diffusée à partir de New York, on sait que cette lettre fut reprise et publiée au Canada. Sans doute ce regret est-il, pour partie, lié au choix d'un plan strictement chronologique.

D'autre part, Frédéric Smith nous montre combien l'implantation de la France libre fut également contrariée par les divisions incessantes des communautés française et canadienne-française, de Montréal notamment : rivalités profondes entre partisans et opposants à la France libre ou à Vichy et, mieux encore, querelles intestines constantes au sein même des milieux "gaullistes ». À cet égard, un regard "genré» est intéressant et l'auteur nous donne à voir de belles crispations misogynes (p. 69, 87, 185-187), de la part de militants qui ont bien du mal à admettre que la France libre, puis la France combattante, soit principalement incarnée au Canada par des femmes (Marthe Simard, Élisabeth de Miribel).

Au-delà d'inévitables similitudes, la valeur ajoutée de cet ouvrage réside dans sa complémentarité avec les études antérieures (outre Éric Amyot, Patrick Lambert ou Charles Halary) qui témoignaient d'un tropisme plus marqué en faveur de Montréal ou d'Ottawa. Ici, l'auteur appréhende davantage la scène de Québec, non sans des développements intéressants sur son milieu universitaire, tant côté enseignant (Auguste Viatte, Charles de Koninck, le père Delos...) que côté étudiant (cf. leurs manifestations pour la France libre, en septembre 1942 et 1943, p. 142, 177). Ce rééquilibrage est d'autant plus le bienvenu que les milieux québécois apparaissent plus précocement et durablement perméables à la cause de la France libre que la société montréalaise, qui reste longtemps plus rétive, voire un véritable "point noir » (p. 63), y compris à l'échelle de l'ensemble du Canada. 
La principale qualité de ce livre, et sans aucun doute son apport à l'histoire des rapports du Québec à la France libre, mais aussi à l'histoire des femmes, repose sur sa capacité à mettre en question un silence historiographique. En effet, Jean-François Muracciole, dans son ouvrage de référence Les Français libres: l'autre Résistance (Paris, Tallandier, 2009), rappelait déjà combien les femmes comptent parmi les oubliés de la France libre, insistant sur leur "place paradoxale" au sein d'un mouvement qui, tout en leur reconnaissant un statut officiel à une époque où les Françaises étaient encore privées du droit de vote, "reproduit aussi les ostracismes de sexe de la III République " (p. 49). Jean-François Muracciole ajoutait : "c'est peu dire, concernant les Françaises libres, que l'essentiel demeure à écrire» (p. 45). Force est d'admettre que Frédéric Smith s'y emploie ici efficacement considérant l'omniprésence dans son livre de deux femmes majeures, Élisabeth de Miribel et Marthe Simard. C'est sur cette dernière que le livre est le plus novateur. En effet, Marthe Simard est une pionnière de la France libre et de la vie politique française qui était tombée jusqu'alors dans les oubliettes de l'histoire et de nombreux historiens. Et pourtant, véritable cheville ouvrière du Comité France libre de Québec, où elle développe une activité intense, elle fut en 1943-1944 la seule femme nommée (dès l'origine) à avoir véritablement siégé à l'Assemblée consultative provisoire d'Alger (Lucie Aubrac, désignée en même temps, était au départ dans l'incapacité de le faire). Dans son cas, il apparaît qu'elle fut non seulement oubliée en tant que femme, mais aussi, paradoxalement, éclipsée dans l'historiographie par une autre femme, Élisabeth de Miribel. C’est donc le grand mérite de Frédéric Smith que de réparer cette injustice et de combler ce vide en nous brossant au fil de son ouvrage le portrait documenté et attachant de cette femme de conviction et d'action.

Marc Bergère

Université Rennes 2 